\title{
La lexicografía amerindia temática: el Compendio de nombres en lengua cakchiquel (1704) de Pantaleón de Guzmán
}

\author{
María Ángeles García Aranda* \\ Universidad Complutense de Madrid, España
}

\begin{abstract}
Resumen
Este artículo presenta un análisis detallado del Compendio de nombres en lengua cakchiquel de Pantaleón de Guzmán, obra que muestra la labor lingüística realizada por los misioneros en el Nuevo Mundo. La evangelización de las tierras conquistadas originó la necesidad de aprender las lenguas indígenas $\mathrm{y}$, como consecuencia, la composición de diccionarios y gramáticas que facilitasen la conversión de los indios. Una de estas obras fue el Compendio de Pantaleón de Guzmán, repertorio que ordena sus materiales por ámbitos designativos, que se enfrenta a los problemas que causan las diferencias entre el español y el cakchiquel y que muestra en sus páginas una gran riqueza léxica (indigenismos, neologismos e hispanismos). Supone, en definitiva, una interesante aportación a la historia de la lingüística y la lexicografía misioneras.
\end{abstract}

Palabras clave: lexicografía, nomenclaturas, lenguas indígenas, cakchiquel, siglo XVIII

૫ Para correspondencia, dirigirse a: María Ángeles García Aranda (magaranda@filol. ucm.es), Universidad Complutense de Madrid, Departamento de Lengua española y Teoría de la Literatura y Literatura comparada, Facultad de Filología, edificio D, Ciudad Universitaria s/n, 28003 Madrid, España. 


\title{
Amerindian thematic leXicogRAPHY: THE COMPENDIO DE NOMBRES
} en lenGUa CAKCHIQUel (1704) By PANTALeÓN DE GuZMÁN

\begin{abstract}
This paper presents a detailed analysis of the Compendio de nombres en lengua cakchiquel of Pantaleón de Guzmán, work that shows the linguistic task realized by the missionaries in the New World. The evangelism of the conquered lands caused the need to learn the indigenous languages and, therefore, the composition of dictionaries and grammars that could help the conversion of Indians. One of these works was Pantaleón de Guzmán's Compendio, subjects catalogued by scopes, facing the problems that cause the differences between Spanish and Cakchiquel and that shows in its pages a great lexical richness. In short, an interesting contribution to the missionary history of Linguistics and Lexicography.
\end{abstract}

Keywords: Lexicography, Nomenclatures, Amerindian languages, cakchiquel, 18th century.

Recibido: 07/03/14

Aceptado: 25/11/14

\section{INTRODUCCIÓN}

En 1704 el franciscano Pantaleón de Guzmán finaliza su Libro yntitulado Compendio de nombres en lengua cakchiquel, volumen bilingüe españolcakchiquel que reúne en sus páginas, además de varias oraciones y textos cristianos, una nomenclatura, esto es, un repertorio léxico temático que organiza el vocabulario en ámbitos designativos como nombres de plantas, de animales, de enfermedades, partes del cuerpo humano o nombres de parentesco. Este compendio, que poco tiene que ver con el resto de la lexicografía amerindia -mayoritariamente alfabética y confeccionada a partir del Vocabulario español-latino de Antonio de Nebrija y del Vocabulario en la lengua castellana y mexicana de Alonso de Molina (México, Juan Pablos, 1555)- constituye una interesante aportación a la lingüística misionera, al corpus de textos "realizados por clérigos cristianos y con el objetivo de facilitar mediante el acceso a tales lenguas la evangelización de los pueblos 
que las hablaban" (Ridruejo 2007: 435) y que no siempre han merecido la atención que merecen ${ }^{1}$.

Estas razones explican la necesidad de un análisis detallado del Compendio de Pantaléon de Guzmán, lo que, sin duda alguna, supone una contribución a la lingüística misionera ${ }^{2}$ en general y a la del español con el cakchiquel (peor conocida en la actualidad que la de otras áreas geográficas) en particular.

\section{LENGUA Y EVANGELIZACIÓN: EL CONTEXTO DEL COMPENDIO}

Pantaleón de Guzmán, Procurador General de Provincia de la Orden de San Francisco, acabó de redactar el Compendio en Santa María de Jesús Paché, curato que ocupaba desde el año 1700 y al que llegó tras haber pasado por San Juan de Alotenango y San Antonio Nejapa (cfr. Acuña 1984), poblaciones muy cercanas a la capital de Guatemala ${ }^{3}$ en las que se hablaba el cakchiquel, una de las más importantes en la Guatemala colonial, junto al quiché y el zutuhil, y que los misioneros debían conocer si querían llevar a los indígenas la palabra de Dios, principal misión en la conquista del Nuevo Mundo:

la Corona consideró, al recibir por donación el dominio y administración del Nuevo Mundo, que su misión primordial consistía en llevar a los naturales la luz evangélica. Con las concesiones pontificias vino a establecerse un mecanismo, el Regio Patronato Indiano, por el que se regulaba y atendía todo lo referente a la tarea espiritual, desde el nombramiento de las autoridades eclesiásticas, la edificación de templos y sostenimiento del clero, la percepción de los diezmos y la censura o

1 Los principales trabajos sobre nomenclaturas del español (por ejemplo, Alvar Ezquerra 1987 y Ayala Castro 1992a y 1992b) solo se han ocupado de los repertorios temáticos del español con el latín o del español con otras lenguas modernas. De manera reciente, citan este Compendio solo Alvar Ezquerra 2013 y García Aranda 2013.

2 Cfr. Koerner 2006, Smith Stark 2010, Suárez Roca 1991 y 1992, Zimmermann 1997 y Zwartjes 2000 .

3 En la actualidad, y tras diversas divisiones administrativas y políticas producidas a lo largo de la historia, Santa María de Jesús Paché y San Juan de Alotenango pertenecen al Departamento de Sacatepéquez y San Antonio Nejapa al vecino Departamento de Chimaltenango. 
aprobación a las disposiciones pontificias en que consistía el Regio Pase. Será el Real Patronato el encargado de apoyar la labor evangélica, pero también el que dé a la Iglesia una serie de directrices, muchas de ellas más políticas que espirituales (Lucena Samoral 1982: 480).

Sobre Guzmán, y sobre otros franciscanos dominicos y jesuitas, recayó, no sin problemas ni rivalidades ${ }^{4}$, el peso de la evangelización, evangelización que se realizó a través de las lenguas de los nativos, pues, aunque a lo largo del siglo XVI se legisló -las Leyes de Burgos de 1512, de Valladolid de 1513 y la Cédula Real del 3 de julio de 1596 son muestra de ello-para imponer el uso del castellano a los indios, la lentitud del procedimiento hizo desistir a la Iglesia, que cambió radicalmente de estrategia: en lugar de que los indios aprendieran el español, aconseja a sus misioneros el aprendizaje de las lenguas indígenas; de esa manera, se aseguraba la rápida y asequible cristianización de los indios. Por ello, se impone una política lingüística que exige el conocimiento de las lenguas nativas ${ }^{5}$,

Felipe II dispone en 1574, 1578 y 1580 que la evangelización tuviera lugar en la lengua de los indios y que en todos los cargos eclesiásticos se prefiera a los que las dominen. En los concilios de Lima de 1582-83

4 García Ruiz (1992) relata en su trabajo "El misionero, las lenguas mayas y la traducción. Nominalismo, Tomismo y Etnolingüismo en Guatemala" los enfrentamientos entre dominicos y franciscanos por las traducciones a las lenguas indígenas de algunos conceptos de la religión católica, "En 1546 ve la luz, en México, la Doctrina christiana breue traduzida en lengua mexicana por el franciscano fray Alonso de Molina. Esta publicación marca el punto de partida del enfrentamiento [...]. Se trataba, en realidad, de un enfrentamiento teológico-filosófico donde, como en una filigrana, cada parte intentaba afirmar las respectivas posiciones y de cuyo desenlace dependía, en última instancia, la predominancia y el control de la interpretación de la fe en el Nuevo Mundo. Y fue un verdadero conflicto ideológico en relación con la traducción de conceptos específicos: no solamente sobre la noción de «dios», sino sobre otros muchos términos, entre los cuales estaban «penitencia», «contrición», «gracia», «alma» o «pecado». A partir de este momento se instaura una verdadera competencia entre las dos órdenes para que se valore e imponga su Doctrina, es decir, su interpretación teológica y sus posiciones ideológicas: entre 1546 y 1553, aparecieron no menos de siete Doctrinas".

5 A lo largo del siglo XVII se promulgaron Cédulas Reales (1603, 1618, 1619, 1624 y 1637) "conducentes a vigilar y comprobar el nivel de conocimiento de lenguas nativas que debían tener los sacerdotes encargados de las parroquias. En ocasiones se llega a sancionar económicamente a los sacerdotes que desconozcan el idioma de sus feligreses -como aparece recogido en la Real Cédula de 2 de diciembre de 1578-o, incluso, a removerlos de sus cargos" (Sueiro Justel 2002: 46-47). De la misma manera, Medina Escudero (1988: 171) recoge el fragmento de las Actas del Capítulo Provincial del 10 de mayo de 1654 en el que se ordena y manda "con todo rigor a todos los hermanos jóvenes, lo mismo a los que ya están asignados a los pueblos de los indios que a los que hayan de ser asignados, que se consagren y pongan todo el empeño posible en aprender el idioma de los indios". 
y en el de México de 1584 se insta a los curas a que erijan escuelas de castellano para los niños indígenas, pero los ministros indios, para alcanzar el curato, debían conocer la lengua de sus feligreses. En 1580 y 1582 dos reales cédulas insisten en lo mismo. Finalmente, en 1580 en las Leyes de Indias, Libro I, título XxII, ley 46, se instituían cátedras de lengua general del país en las Universidades de Lima y México, aunque la de esta última ciudad no funciona hasta 1626 (Ridruejo 2007: 440).

La necesidad de aprender las lenguas indígenas lleva a numerosos misioneros, a quienes se les acabó exigiendo un título universitario ${ }^{6}$, a componer gramáticas y vocabularios de las lenguas indígenas, $\mathrm{y}$, en el caso de Guatemala, especialmente del cakchiquel (lengua que debió alcanzar cierto prestigio e importancia en la época, pues entre las primeras cátedras de la Universidad de San Carlos de Guatemala -fundada en 1676- se encontraba la Prima de cakchiquel). Es así como surge el Libro yntitulado Compendio de nombres en lengua cakchiquel, y significados de verbos por ymperatiuo y acusativo, recíprocos, en doçe tratados de Pantaleón de Guzmán, obra compuesta con una motivación, unos intereses y unas fuentes similares a los del resto de producción sobre el cakchiquel:

- El Vocabulario en lengua castellana y guatemalteca que se llama cakchiquel chi de Juan Alonso (finales del XVI), que, según Francisco Vázquez (1714 [1937-1944]: II, 229), "sirvió mucho a los ministros que le siguieron, ampliando otros, hasta llegar a la perfección que hoy tiene el libro ms. que está en la librería de este convento llamado vulgarmente Calepino en lengua de los indios".

- El Vocabulario en lengua castellana cachiquel chi y quiché chi; en la primera división se pone la lengua castellana, en la $2^{a}$ la cachiquely en la $3^{a}$ quiché ("acabelo en este pueblo de Sacualpa a 16 de noviembre de 1695", hoja 194) de Domingo de Basseta, repertorio alfabético español-cakchiquel y cakchiquel-español (interrumpido en la letra I) que parece, a falta de un estudio más detallado, una adaptación del Vocabulario en lengua castellana y mexicana y mexicana $y$ castellana de Alonso de Molina (1555), pues las mismas entradas españolas tienen en aquel el equivalente en cakchiquel y en este en

\footnotetext{
6 Según Sueiro Justel (2002: 47) "llegaron a crearse en América una cincuentena de centros de estudios superiores. Según ordenaba el monarca, nadie podía recibir órdenes sacerdotales sin haber aprobado antes, en la Universidad respectiva, un curso completo en la lengua de los indios y nadie debía postularse para un curato indígena, si no había rendido el correspondiente examen del idioma ante los profesores universitarios de esa disciplina".
} 
náhualt. En las últimas páginas, incluye también un Arte gramatical (dieciséis hojas con capítulos sobre preposiciones, conjunciones, comparativos, interrogativos, adverbios, numerales...), un epígrafe sobre "parentescos", otro sobre "membra corporis humani" y una "Doctrina cristiana en lengua cachiquel" (Pater noster, Ave Maria, Credo, Salve Regina, Los mandamientos de la ley de Dios, Los mandamientos de la Santa Madre Iglesia, Los sacramentos, Los artículos de la Fee, La confessión general y Preguntas y respuestas de la doctrina cristiana).

- El Vocabulario de la Lengua Cakchiquel (c. 1650) de Tomás de Coto, "original dentro de la lexicografía hispanoamericana por muchas razones, especialmente por lo que respecta a su técnica" (Hernández 2008a y 2008b: 321-322).

- El Arte de la lengva metropolitana del reyno cakchiquel o gvatemalico, con un paralelo de las lenguas metropolitanas de los reynos kiche, cakchiquel y tzutuhil, que hoy integran el reyno de Guatemala (Guatemala, imprenta de Sebastián de Arévalo, 1753) de José Ildefonso Flores.

- El Vocabulario trilingüe guatemalteco de los tres principales idiomas: kachiquel, quiché y tzutuhil (siglo XvI) -que se conservaba manuscrito en el convento de San Francisco de Guatemala- de fray Francisco Parra.

- La Gramática del idioma cakchiquel del franciscano Carlos Joseph Rosales (1748), que, pese al título, aúna en sus páginas, como era habitual, lengua (capítulos sobre el alfabeto cakchiquel, el nombre, pronombres adjetivos, sustantivos, modo de sustantivar los adjetivos, comparativos y superlativos, verbo sustantivo, partículas, conjugación de los verbos activos, verbales pasivos, gerundios, acusativos para los verbos, derivación y composición de los verbos, de los verbos absolutivos, pasivos, neutros, instrumentales, frecuentativos, defectivos, adverbios, preposiciones de ablativo, interjecciones, etc.) y religión (contiene un "Compendio de la Doctrina Cristiana en cackhiquel y castellano").

- El Vocabulario de la lengua cakchiquel de fray Thomás de Santo Domingo (1693).

- El Arte de lengua cakchiquel (1754) de Esteban Torresano, que no es sino una "enumeración y corrección del Arte de la lengua metropolitana del Reyno cakchiquel o guatemalteco por el P. Ildefonso Joseph Flores, Guatemala, 1753”. 
- El Calepino en lengua cakchiquel de fray Francisco Varea o Verea (copiado en 1699 por Francisco Cerón, guardián del convento de San Pedro de La Laguna).

- Además de la conocida Theologia Indorum, de Algunos sermones en lengua quiché de Rabinal y de un Arte de la lengua quiché o utlatecat, fray Domingo de Vico compuso un Vocabulario de la lengua cakchiquel con advertencia de los vocablos de las lenguas quiché y tzutuhil (c. 1555).

- El Arte y Vocabulario de la lengua cakchiquel (principios del siglo $\mathrm{XVI}$ ) de Benito de Villacañas, inspirado en las Introductiones latinae de Antonio de Nebrija y en el Vocabulario en la lengua castellana y mexicana de Alonso de Molina (México, Juan Pablos, 1555) que, a su vez, presenta una importante deuda con el Vocabulario españollatino de Antonio de Nebrija y que "hecho después de auer tratado quarenta años con los indios de esta lengua sin interrupción".

- Francisco Ximénez, autor de la Historia de la Provincia de San Vicente de Chiapa y Guatemala de la Orden de los Predicadores (1722) y del Párroco perfecto, compuso también un Tesoro de las Lenguas cackchiquel, quiché y tzutuhil, un Arte de las tres lenguas cakchiquel, quiché y tzutuhil, un Vocabulario de la lengua cakchiquel y una transcripción y traducción al español del Popol Vuh que lleva por nombre Empiezan las Historias del origen de los indios de esta Provincia de Guatemala y que recoge leyendas y mitos (mezcladas con la historia) del pueblo quiché.

Lingüísticamente, el valor de cada uno de estos escritos varía, pues algunos, como a este lado del Atlántico, son originales y curiosos, otros completas descripciones de lenguas indígenas y otros simples copias sin apenas interés. Los repertorios léxicos parecen tener como modelo el Vocabulario en la lengua castellana y mexicana de Alonso de Molina (México, Juan Pablos, 1555), quien, a su vez, se inspiró en el Vocabulario español-latino de Antonio de Nebrija; mientras que las gramáticas, de manera general, "continúan las mismas o parecidas pautas productivas que habían seguido las primeras gramáticas de las lenguas vulgares europeas recogiendo y aplicando los modelos y las categorías de las gramáticas latinas" (Ridruejo 2007: 450). 


\section{EL COMPENDIO DE NOMBRES EN LENGUA CAKCHIQUEL. CONTENIDO Y ESTRUCTURA}

Pese a que René Acuña (en Guzmán 1704 [1984]: XII), autor de la edición facsímil del Compendio ${ }^{7}$, afirma que "lo que caracteriza a este Compendio es el inesperado orden analítico, digno de una mentalidad más moderna, con que se distribuyen las voces del cakchiquel", no debe olvidarse que estos repertorios temáticos ordenados por ámbitos designativos -conocidos como nomenclaturas - venían utilizándose en la enseñanza de segundas lenguas desde la Antigüedad clásica, y debieron ser adaptados en América para el aprendizaje de las lenguas amerindias, tal y como demuestran no solo este Compendio sino también los breves vocabularios temáticos encontrados en la mayoría de manuscritos de contenido gramatical y léxico (normalmente repertorios alfabéticos).

\subsection{DisPOSICIÓN DE LOS MATERIALES}

El Compendio de nombres en lengua cakchiquel recoge en doce tratados, por un lado, el léxico de una serie de ámbitos designativos y, por otro, oraciones, canciones y romances, esto es, se entremezclan contenidos lingüísticos, etnográficos y religiosos, español, cakchiquel y latín, lo que era habitual, dado el contexto descrito anteriormente, en las obras compuestas por los misioneros.

El contenido de los tratados es el siguiente:

- Tratado primero: nombres de árboles frutales, nombres de árboles silvestres, nombres de árboles aromáticos y nombres de resinas de árboles (174 entradas).

- Tratado segundo: nombres de yerbas comestibles, nombres de yerbas medicinales, nombres de yerbas silvestres, nombres de cañas y colores (206 entradas).

7 El ejemplar conservado, editado por René Acuña en 1984 (México, UNAM), se encuentra en la John Carter Brown Library (signatura JCB manuscripts, codex ind 15). Tanto en la Biblioteca de la Universidad de Pensilvania (signatura UPenn Ms. Coll. 700, item 52) como en la Newberry Library de Chicago (colección de Edward E. Ayer, signatura Ayer MS 1501) hay copias de este manuscrito realizadas por Carl Herman Berendt entre 1850 y 1875. 
- Tratado tercero: nombres de piedras preciosas, pedernales y metales, nombres de vientos y planetas y los elementos (237 entradas).

- Tratado cuarto: nombres de animales, nombres de culebras, nombres de gusanos y lombrices, nombres de abejas, avispas y ronrones, nombres de peces y animales acuarios, nombres de aves, nombres de espinas y nombres de enfermedades (532 entradas).

- Tratado quinto: nombres del cuerpo y miembros del hombre y nombres de diversas cosas (3309 entradas); este último es un epígrafe tremendamente heterogéneo en el que, sin aparente orden, Pantaleón de Guzmán recoge las equivalencias cakchiqueles de voces (muchas de ellas repetidas en otros epígrafes) como paciencia, modestia, criado, pecador, gula, ira, remero, trompetero, diluvio, mundo, ampollas, afán o trabajo, cárcel, agradecimiento, pan o tortilla, engrudo, venta, vendedor, tamal, risa o burla, rico, enjambre de avispas, enjambre de abejas, miel silvestre, cosa sencilla, azada, árbol gordo, comida, gran señor, ciudad o pueblo, color verde, cara o rostro, trenzado, cuervo, piedra preciosa, mujer casada, toda cosa necesaria, yerno, verruga, peine, hurto, ladrón, ceniza, hormiga, camino real, desvergüenza, incordio, baño, carrera....así como de frases hechas y expresiones del discurso libre (determinaremos, ya lo tenemos conçertado, entre nosotros, hay gran distançia del uno al otro, poca distançia, pensar unos en otros, no sé quién es o no sé quién sea, no sé cómo lo hagamos, está mi corazón muy triste, estoy haçiendo fuego, está rebentado...).

- Tratado sexto: refranes, frases y modos de hablar (78 entradas), en donde se recogen expresiones como quien a buen árbol se arrima, buena sombra le cobija; los niños y los locos dicen las verdades; muerto el ahijado, acabose el compadrazgo; no se ganó Zamora en una hora; mejor fuera haber estado quieto, y no lo hubieras hecho; me desmayé; estaban pecando dos mujeres; no he entendido lo que me has dicho, ni sé lo que significa, ni lo que dices o quieres decir; son mi tronco mis padres, de ellos vine...

- Tratado séptimo: significados de verbos por imperativo y acusativos recíprocos (2341 entradas), epígrafe que seguramente se explica por la dificultad gramatical del cakchiquel, lengua ergativa, aglutinante -no flexiva como el latín o el español-en la que diferentes lexemas y afijos (morfemas de aspecto, tiempo y modo), con significados diferentes, se unen para formar nuevos signos lingüísticos, en los que son muy frecuentes los cambios morfofonológicos; por eso, la morfología 
cakchiquel se detalla a partir de conceptos como juntar / poner juntos / añadir partículas, anteponer, mudar sílabas, simplicidad del verbo, inhesión de los accidentes o hacer por circunloquios ${ }^{8}$. Como señaló Ildefonso Flores a propósito de la descripción del verbo en su Arte de la lengua metropolitana del reyno cakchiquel (Guatemala, 1753), es "materia difficultosa en esta lengua, y, por la diversidad de sus formaciones, obscura, confusa y extravagante calidad para composición, mas se procurará declara lo mejor y más usual por sus modos y tiempos" (pág. 58).

En esta ocasión, Pantaleón de Guzmán recopila tan solo imperativos (y las partículas con que se forman en función del tipo y terminación del verbo) y formas reflexivas ${ }^{9}$

8 En este sentido, y como señala Ascensión Hernández (2009: 176) para el náhuatl, otra lengua aglutinante, "quizá percibieron [quienes llegaron de lenguas indoeuropeas] que para el estudio de la materia gramatical era muy difícil separar totalmente el contenido morfológico del sintáctico, como en la tradición clásica y por ello, al entrar en la descripción de las categorías gramaticales, tocan necesariamente las posibilidades de componerse unas palabras con otras, tal y como aparecen en la frase. Este hecho es totalmente comprensible si pensamos que en lenguas como el náhuatl rara vez se presentan el nombre, el pronombre y el verbo en estado absoluto; casi siempre aparecen compuestos con pronombres y partículas".

9 Todas las entradas comienzan por tin o tan, partículas utilizadas en cakchiquel para la primera y la segunda persona del singular, respectivamente. 


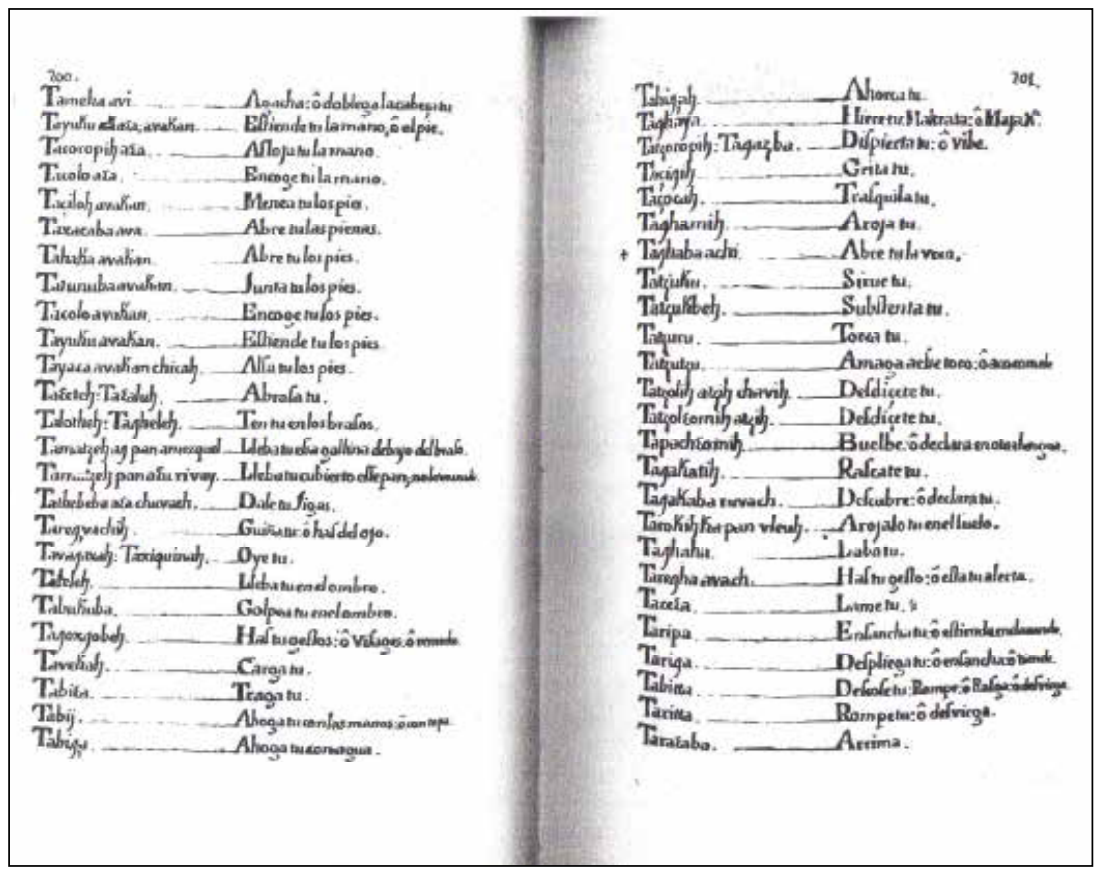

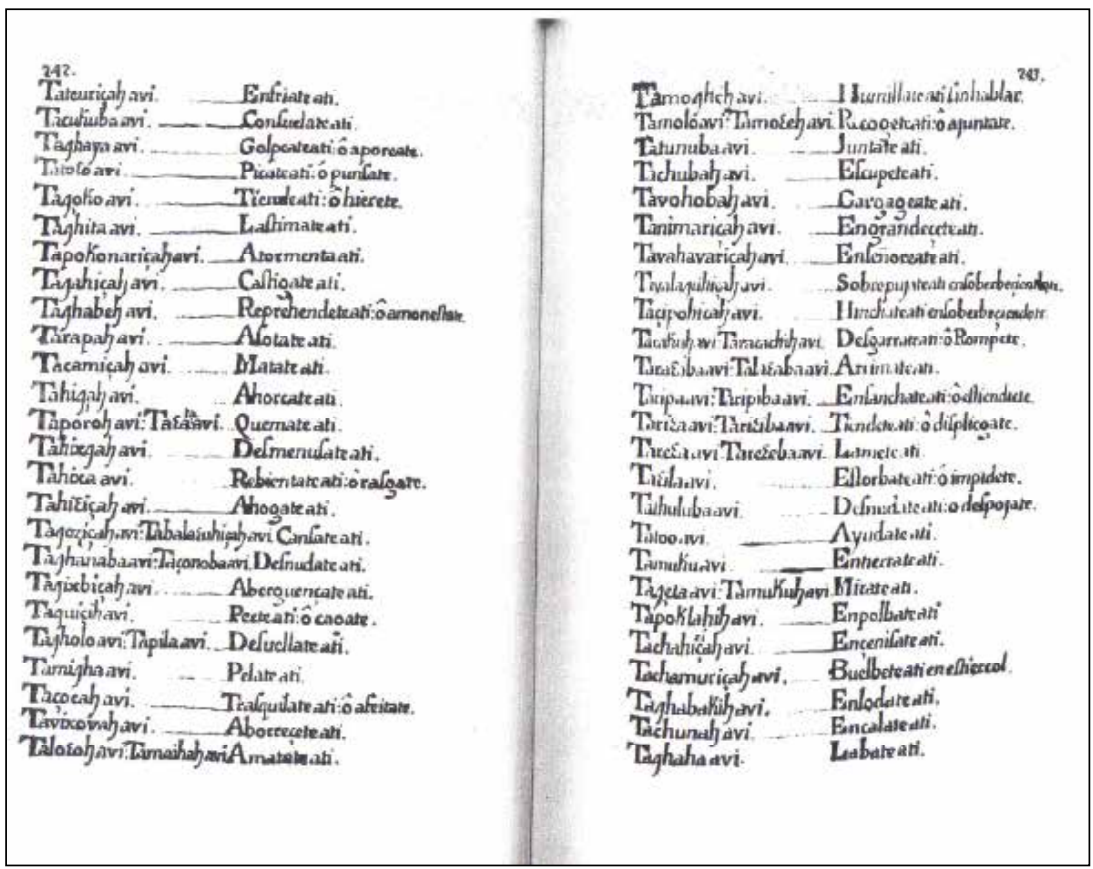


De la misma manera, ejemplifica la formación de la reciprocidad en cakchiquel con varios verbos -en esta lengua, tal y como describen los tratados gramaticales, existen dos tipos de pronombres recíprocos, "los que reciprocan sobre la persona que hace y otros que reciprocan sobre otras personas" (Benito de Villacañas, Arte de la lengua cakhciquel, pág. 12), que conocen además diferentes formas en función del tiempo y modo verbales-.

- Tratado octavo: parentescos (56 entradas), ejercicios espirituales desde que se levanta y la bendición de la mesa y gracias.

- Tratado noveno: disposición del que ha de comulgar; el ánima Christi con su indulgencia; el adórote Santa Cruz, las canciones en Castilla y el alabado en Castilla.

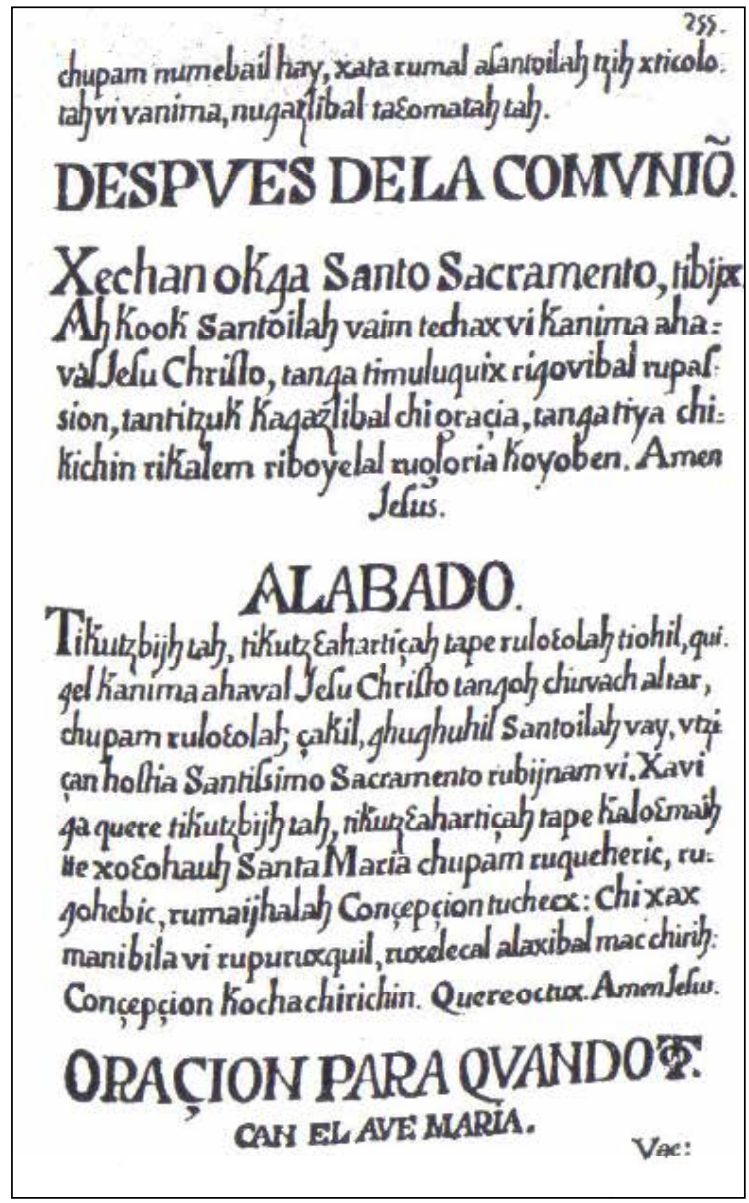


- Tratado décimo: la protestación de fee en Castilla, la protestación de fee en lengua, distribución de los passos del Via Crucis, romance a la lançada de Christo y modo de ayudar a bien morir.

- Tratado undécimo: las oraciones de la doctrina christiana, preguntas de la doctrina christiana, romance al nacimiento de Christo y otro romance al nacimiento de Christo.

- Tratado duodécimo: enigmas o adivinanzas en Castilla y adiçiones de nombres de diversas cosas (121 entradas), entre las que se encuentran voces como cintura, muela cordal, sarpullido, caspa de la cabeza, máscara, azadón de palo, candil, caracol, tela del corazón o traidor. El "carácter misceláneo" de este epígrafe y los numerosos añadidos, con letra diferente, que se encuentran a lo largo del texto llevan a Alvar Ezquerra (2013: 258) a afirmar que "no son de nuestro autor", por lo que habría que pensar en más de una mano en la redacción de la versión final del Compendio.

El amplio número de entradas del Compendio, unas siete mil, no supone, en cambio, la inclusión del léxico básico de una lengua, como ocurre habitualmente con este tipo de repertorios, y deja fuera epígrafes sobre los oficios, los números, la ciudad o el pueblo, la casa, las comidas o las bebidas, que no faltan en la mayoría de nomenclaturas del español.

Por otra parte, y aunque el orden de los artículos dentro de cada epígrafe es aparentemente aleatorio, una mirada atenta sobre ellos nos revela interesantes datos. Por ejemplo, las partes del cuerpo humano son descritas de dentro hacia fuera y desde arriba hacia abajo; las piedras preciosas del diamante al pedernal y el talco; los animales comprenden desde el león, tigre y toro a la araña venenosa. Parece, pues, que bajo la ordenación de estos epígrafes subyacen criterios extralingüísticos de diferente tipo, como, por ejemplo, la mayor importancia de las partes internas del cuerpo humano, por encima de las externas, o de la cabeza por encima de las extremidades inferiores; el valor en los metales y piedras preciosas o, en el epígrafe "Nombres de cientos y planetas", el orden en los movimientos solares (luz, claridad, dia, antes de amanecer, amanecer, mañana, mediodía, noche, oscuridad, noche oscura...) o las fases lunares (luna, menguante de luna, luna nueva, luna creciente, luna llena).

La dificultad de compendiar el léxico de unos cuantos ámbitos designativos acarrea problemas de difícil solución, porque ¿dónde empieza un capítulo y termina otro?, ¿dónde están los límites de cada ámbito designativo?, ¿dónde colocar un término -sobre todo los polisémicos-que tiene cabida en más de un epígrafe?, ¿acaso el autor no ordena el léxico a 
partir de criterios subjetivos que no tienen por qué coincidir con los del lector y que, por tanto, dificultan considerablemente la búsqueda del léxico? La solución más frecuente para resolver algunos de estos problemas es precisamente repetir artículos en diferentes epígrafes, o incluir un epígrafe con "nombres de diversas cosas" que dé cuenta de todo aquello que no ha aparecido en el resto de epígrafes.

Otro rasgo del Compendio, que aunque no es novedoso, sí testimonia la tradición y el alcance que tuvo el método lexicográfico empleado por los primeros autores de repertorios léxicos bilingües, está relacionado con la dependencia interna de los artículos lexicográficos. El diccionario, en épocas pasadas, fue concebido para ser leído y utilizado en su conjunto, y no puntualmente, de manera que para alcanzar el pleno sentido de algunas definiciones y equivalentes era necesario conocer los artículos precedentes (Alvar Ezquerra 1987: 19-23). Algo parecido ocurre con este repertorio ${ }^{10}$ :

10 Pese a que Pantaleón de Guzmán no dedica ninguna línea a la explicación de la pronunciación y de la escritura en cakchiquel, es claro que debió conocer otros materiales en los que sí se atendía a estos aspectos, pues utiliza los tresillos (tres al revés) y cuatrillos inventados por Francisco de la Parra para la representación de los sonidos propios de esta lengua (y que hemos tratado de respetar en nuestra transcripción), "las letras propias y características de este idioma, que no se hallan en ninguno otro, son las que con especialíssimo cuydado y reflexión inventó nuestro ingeniosísimo P. Fr. Francisco de la Parra, tan propias para este idioma que parecen naturalmente expresivas de sus diversos conceptos. Son pues 4. 4; $\varepsilon$. tz. 4h" (Ildefonso Flores 1753: 7).

En la actualidad, estos símbolos se corresponden, según el Alfabeto para los cuatro idiomas indigenas mayoritarios de Guatemala (1950: 18) y Los idiomas mayas de Guatemala (1993: 123), con

4 = k' ("la $k$ seguida de apóstrofo representa un sonido mucho más profundo y cerrado que el de la $k$, emitiéndose con un cerrar y abrir de las cuerdas vocales, con ayuda de la uvular"),

$4,=$ tz' ("La $t z$ juntas seguidas de apóstrofo representan el sonido glotalizado de la $t z$ "),

$\varepsilon=$ q' ("la $q$ seguida de apóstrofo representa el mismo sonido de la c' [ $c$ glotalizada, representa un sonido que se reproduce en la misma posición de la $c$ castellana, a diferencia de un cerrar y abrir de las cuerdas vocales durante la emisión del sonido, con lo cual se produce un casquido en la velar] y se usa antes de $e$ y de $i$, con una $u$ de por medio para seguir la regla del castellano que, y qui"),

$\mathrm{tz}=\mathrm{tz}$ ("la $t z$ juntas representan un sonido alveolar, para cuya reproducción se disponen los elementos vocales para producir $s$ y se pronuncia $t$, como en quetzal'),

$4 \mathrm{~h}=\mathrm{ch}$ ' "la ch seguida de apóstrofo representa un sonido que se produce en la misma posición de la ch castellana, a diferencia de que esta ch' es glotalizada”). 
Rucheeleacohchijh, el árbol de algodón pardo

Ruchihol, su hilo [Nombres de árboles aromáticos]

4ual, el diamante

Yamanic, la esmeralda

Ruvixiquin, cuxquet eop, los sarcillos

Chachal, la gargantilla

Chuncu, Ealea, las manillas

Napea, la sortija [Nombres de piedras preciosas]

Ruchicopilcab, abeja de miel

Vinak cab, abeja de miel

4ubuh, enjambre de abejas

Ykanih, yboyçital, toeoy, enjambre de avispas

Akah, el panal de avispa

Otokom, hooh, la colmena

Cakicab, ruyaalche, la miel blanca

Pancheel, la miel silvestre [Nombres de abejas, avispas y ronrones]

\subsection{LA MiCROESTRUCTURA}

El artículo lexicográfico se caracteriza por la sencillez tanto formal como de contenido. La estructura más frecuente que aparece en el repertorio es la aposición: entrada cakchiquel + correspondencia española, que puede ser simple o compleja, es decir, estar compuesta o bien de un solo equivalente español o bien de una unidad pluriverbal de diferente contenido, a saber, a) voces sinónimas o intercambiables en alguno de sus usos, lo que permite delimitar el significado y la acepción correctos, y b) para evitar confusiones y dejar claro el significado de cada una de las voces, Pantaleón de Guzmán, siguiendo la técnica lexicográfica inaugurada por Antonio de Nebrija, introduce o bien una pseudodefinición o bien, en aquellos casos en que tiene problemas para encontrar un equivalente a la voz cakchiquel (lo que ocurre con las realidades americanas, fundamentalmente flora y fauna, que eran inexistentes en la Península y que debía detallar en función de sus conocimientos y de sus circunstancias), una superficial descripción del objeto, planta o animal a que se refiere, $o$, en los casos más difíciles, una simple presentación. Veamos algunos ejemplos: 
Equivalentes sinonímicos

4echelah, la montaña

Yubak rupa eor, la lebadura

Tzolih, la salbia

4im, la paxa

To4, el pedernal

Bax, el yeso

Vouh, el bidrio

Ral4ha, la ballesta

Pubanel, el tirador

Xmucur, la tórtola

Xayon, la perdiz

Equivalentes complejos: sinónimos

Huyu, el monte o çierra

Chapaban 4am, las parras o vides

Ruxe4ul, la çarçaparrilla o palo de la vida

Avuk, rugiya, la nuria o perrito de agua

4hac, llaga o bubas o lamparones

Ruçal 4i, la tiña o empeyne perruno

Tamuh, el tonto o bobo

4huh, el loco o alunado

Ahxul, el flauter o pitero

Hucu, la canoa, barca o navío

Puz, naual, el encantador o brujo

Varay bey, atalaya o espía

Vach, la cara o haz o presencia

Vachibal, la ymagen o semejanza

Vinakchi, pleyto o queja

Vtiuh, los coyotes o lobos

Ahqueel, la molender o panadera

Ohobal, el tragadero o garguero

Ochoch, la casa, morada, pueblo o lugar

Equivalentes complejos: pseudodefiniciones

4hatan4hi4h, la cama de fierro o la parrilla

Raxєab, el çereno o rocío de la noche

4hogeh rumatz, mal mortal, es como calambre en las tripas

Pixtum, el pixton, tortilla gruesa

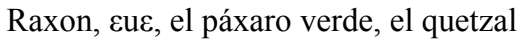

Xolobachan, el abismo, hoyo muy hondo 
V4abal, la xícara o taça en que se bebe

Pazanchi4ul, faxado o envuelto con manta

Pok, el cascajo o arena blanca

Puhvi, el blochudo, aver que anda de noche

Yacolvay, yacolya, el maestresala, o el que sirve en la mesa

Ey, vcy, los dientes, o filo de cuchillo

Equivalentes complejos: descripciones

Un árbol grande, un árbol como el de madre de cacao, un árbol que con sus hojas envuelven el tamal, un árbol colorado y tiñen con él, un árbol que su fruta echa leche, un árbol muy grande, un árbol muy grande delgado, un árbol fuerte blanco, un árbol de que hacen horquetas, un árbol delgado fuerte, un árbol que tiene flores blancas, un árbol de que hacen casas, una yerba que se come sin sal, unas hojas que ponen en las fuentes, unas hojas para curar quebraduras de hueso, una yerba que cursa el mal de orina, una caña agria que cura la purgación, una yerba que cura las almorranas, una yerba para curar la sarna, una yerba con que lavan, una yerba que comen las bestias, unos arbolillos espinosos, una yerba con que barren los hornos, unas cañas agrias medicinales, un género de caña pequeña bermeja, la hormiga bermeja, el sapo muy grande, otro género de sapo grande, otro género de sapo, hormiga brava negra, hormiga mayor y brava, hormiga ponzoñosa, hormigas grandes pintadas, araña grande no ponzoñosa, araña ponzoñosa, araña que pica las bestias, mosquitos muy pequeños, mosquitos que pican de noche, araña venenosa, víbora grande de la tierra caliente, víbora delgada colorada, víbora delgada amarilla, víbora delgada y seca, víbora delgada que se anda en los pies, víbora muy grande, la víbora verde voladora, la víbora de la nariz partida, otro género de víbora negra, otro género de víbora colorada, otro género de víbora blanca, otro género de víbora seca, unas culebras negras muy grandes y largas que andas en los lodos o junto a los ríos, la culebra boba que no pica, gusano peludo colorado, gusano peludo negro, gusano que tiene cachitos en la cabeza, gusanillo peludo, gusano que se cría en los árboles, gusano que se enrosca, gusano delgado con muchos pies, gusano de yerbas y frutas, gusano de mazorca de maíz, gusano de carne, avispa grande negra que pica, avispa grande bermeja que pica, avispa que hacen sus paneles en la pared, abejón de miel que cría debajo de tierra, abejón de miel que cría de suciedades...

Otro de los rasgos del Compendio, habitual en las nomenclaturas bilingües de los siglos XVI y XVII, es que se repitan equivalentes españoles para diferentes voces cakchiqueles, sin explicar, dada la brevedad del artículo lexicográfico, la diferencia en cada caso. 
Hix 4, la berruga o mesquino

Xuy, el mesquino o la berruga

Çiçon, muliçiçon, arador de la mano

Çanic belehyue, arador de la mano

Rabah xoc, los callos de las manos

Tantipoli kaea, los callos de las manos

Teuh eatan, fríos y calenturas

Rax teuh, fríos y calenturas

Ma4ą4, ruvach, tuerto de un ojo

Tzoy runas ruvach, tuerto de un ojo

Roboric runae ruvach, tuerto de un ojo

Çoppoçic ruvach, tuerto de un ojo

Yobboic ruvach, tuerto de un ojo

Hebehic ruvach, tuerto de un ojo

Hetehic ruvach, tuerto de un ojo

Lamaloh yuchi, el desdentado

Mani rey, el desdentado

4inin rey, el dientudo

Vaghavaxinak eyah, el dientudo

Xilim, bubas

Xilim Ahu, bubas

Çobahauh, bubas

Çobi 4hac, bubas

Popoxlech, la tortilla seca

Chakih vay, la tortilla seca

En otras ocasiones, el Compendio, como solo ofrece equivalentes y no definiciones, incorpora, junto al equivalente español, diferentes unidades que ayudan a determinar el contexto y, por tanto, a facilitar la comprensión de una determinada voz, como en, la red para cazar aves, la trampa para cazar animales, el salteador de caminos, la resina del árbol, los padrastros de los dedos, el yunque del herrero, manco de las manos, madriguera de conejos, hilo de lana...

Por otro lado, las diferencias entre ambas lenguas explican tanto la aparición de información gramatical en algunos artículos lexicográficos, como la presencia de otros que contienen ejemplos de uso o, en el caso del 
epígrafe dedicado a los parentescos, la especial disposición del contenido del capítulo, en donde se tiene que hacer referencia necesariamente a si el parentesco es con respecto a un hombre o a una mujer ${ }^{11}$.

Cani, canih, adverbio: luego

Caniquibe, canihquibe, luego hoy

Cami, adverbio: ahora

Cami, cami xcatul, ahora, ahora as de venir

Coco, chuca, adverbio: presto

$\mathrm{Ba}$, adverbio: donde

Bala, balahe, Balahetak, no sé dónde

Banaa, no sé dónde

Can, partículo de pretérito y futuro

Chuxecan xnubihvichavichin, al prinçipio os dige

Xnubih can, dejéselo dicho

Tinbin can, se lo dexaré dicho

Cahlahuh, catorçe

Cahlauheh, de aquí a catorce días

Cahlauheherm catorçe días a

Benakil, muchas veçes

Maquibenakil quinul yvi4in, no vengo muchas veçes a visitaros

Benakil Tinian, hágalo muchas veçes

Bij amac, el estrangero

Maxayn ama $\varepsilon$ chave?, tiénesme por estrangero?

11 Pantaleón de Guzmán, como otros muchos gramáticos y lexicógrafos del cakchiquel, debe dar cuenta tanto de los posesivos (esta lengua codifica morfológicamente la posesión y el poseedor, y varía las formas en función de la terminación, vocálica o consonántica, del sustantivo) como de las relaciones de parentesco (el cakchiquel las describe más pormenorizadamente que el español; así, resumían este hecho Alfredo Herburger y Eduardo Díaz Barrios (1956: 55): "Muchos de los nombres de parientes cambian, según sean dichos por un hombre o por una mujer. Así, por ejemplo, la palabra cakchiquel baluk quiere decir "cuñado" dicha por un hombre, mientras que esa palabra dicha por una mujer es wechán. En cakchiquel la palabra "hijo" dicha por un hombre es cajohl, mientras que dicha por una mujer es wahl. La palabra cakchiquel mealh quiere decir "hija" dicha por un hombre, mientras que la mujer debe de decir walh; un mam quiere decir "mi nieto" dicha por un hombre, mientras que la mujer debe de decir wij para decir "mi nieto". 
Alahibal, la burla

Xa alah vichin, estoy burlando

Xa alah xapetze tantikaban, estamos burlando

Katze, kalah tantikaban, estamos burlando

\begin{tabular}{|c|c|}
\hline 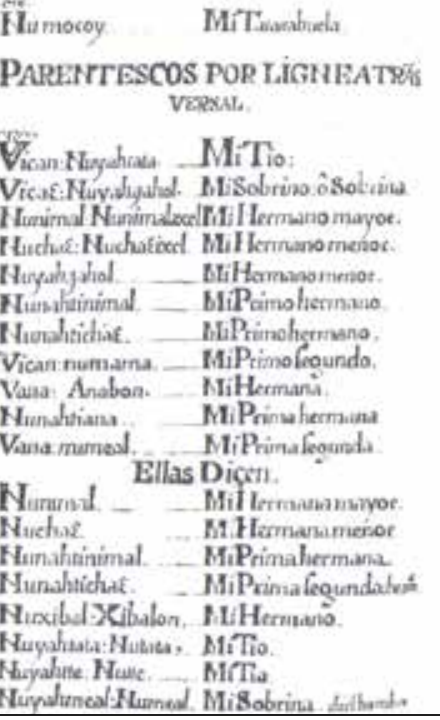 & 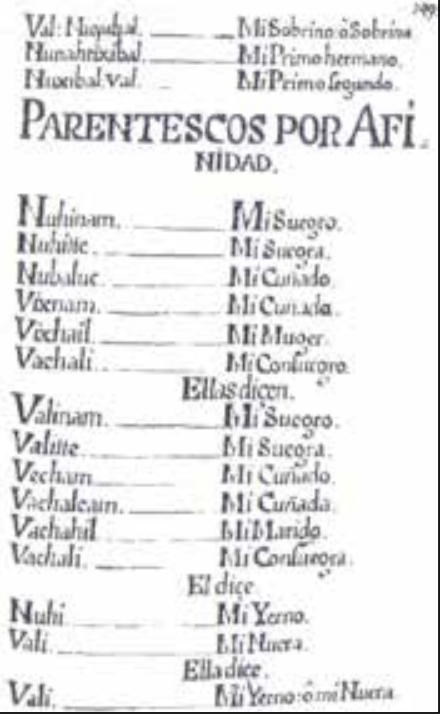 \\
\hline
\end{tabular}

En definitiva, el Compendio muestra unos artículos lexicográficos muy poco sistemáticos; equivalentes repetidos; sustantivos, verbos, adverbios y adjetivos junto a unidades o frases del discurso libre; introducción, en unos pocos casos, de información gramatical... Pese a todo, estos rasgos no son novedosos en la historia de los diccionarios del español, sino que la mayoría es fruto de la técnica lexicográfica, joven y poco elaborada todavía para los repertorios del español con lenguas amerindias, así como de la necesidad de codificar una lengua muy diferente, alejada y poco conocida con recursos tremendamente limitados.

\subsection{CAKChiQuel y eSPAÑol, LENGUAS EN CONTACTO}

Como se ha señalado en múltiples ocasiones (Aleza Izquierdo - Enguita Utrilla 2002, Alvar 1997, Fontanella de Weinberg 1992, Frago Gracia 1999, de Granda 1994, Lipski 1996, López Morales 1998, Ramírez Luengo 2007, Rivarola 2000, Sánchez Méndez 2003, Vaquero 1996), el contacto con 
la nueva realidad americana obligó a los colonizadores a asignar nuevos nombres a los referentes que encontraron a su llegada al Nuevo Mundo (sobre todo, aunque no solo, plantas y animales), lo que tuvo consecuencias lingüísticas tanto para el español como para las lenguas amerindias.

Esta situación está bien reflejada en el Compendio de Pantaleón de Guzmán -fundamentalmente en los epígrafes de fauna y flora americanas-, en donde se encuentran buenas muestras de la adaptación de voces patrimoniales a la nueva realidad, de la creación de nuevas voces, de la presencia de americanismos, de la mezcla de ambas lenguas y de la cakchiquelización de voces hispanas ${ }^{12}$, a saber:

1. Adaptación del léxico patrimonial a la nueva realidad, para lo que se experimentaron diferentes soluciones

1.1. Empleo de voces españolas, sin modificación alguna, para la designación de nuevas realidades. Gracias a los testimonios de historiadores, cronistas, naturalistas o conquistadores (Cristóbal Colón, Fray Bartolomé de las Casas, Hernán Cortés, Bernal Díaz del Castillo, Albar Núñez Cabeza de Vaca, Juan de Castellanos, Gonzalo Fernández de Oviedo, entre otros) ${ }^{13}$, sabemos que se utilizaron las denominaciones existentes para aquellos referentes americanos que guardaban algún parecido con los españoles, aunque hubiese diferencias; así, por ejemplo, José de Acosta en su Historia natural y moral de las Indias (1590 [1987]: 263) afirma que "algún tiempo dudé si el plátano que los antiguos celebraron, y este de Indias, era de una especie; mas visto lo que es éste, y lo que del otro escriben, no hay duda de que son diversísimos. La causa de haberle llamado plátano los españoles (porque los naturales no tenían tal vocablo) fue, como en otras cosas, alguna similitud que hallaron, como llaman ciruelas y piñas y almendras y pepinos, cosas tan diferentes de las que en Castilla son de esos géneros" (cfr. Torres Torres 1998).

Ahora bien, Pantaleón de Guzmán, a diferencia de otros autores, no ofrece descripción alguna del referente, por lo que, en ocasiones, es difícil conocer los parecidos que determinan una u otra denominación: níspero, plátano, cebollas, espinacas, frijoles, piñas, pepinos, león, dátil, albaricoque, mora, pera, higo, limón, membrillo, saúco, cedro, víbora, jazmín...

12 Sigo el orden que aparece en Ramírez Luengo 2007: 72-80.

13 Véase en este sentido Enguita Utrilla (2004), quien analiza, a partir de las obras de Fernández de Oviedo, Hernán Cortés, José de Acosta, Góngora de Marmolejo, Bartolomé Lorenzo y Cristóbal de Molina, las innovaciones léxicas del español en el primer siglo de la conquista y colonización de América. 
1.2. Creación, por medio de derivación, de un nuevo vocablo para denominar el referente americano: piñuelas, higuerilla, aguacatillo, garrapatilla, piojito, camaroncitos, cangrejitos, gavilancillo, tortuguita, venadito, abejita, gusanillo, pajarico ${ }^{14} \ldots$

1.3. Otras veces, en cambio, los lexicógrafos se sirven de un complemento que acompaña a la voz española y que da cuenta del parecido, que no de la identidad, que existe entre los referentes: caña de Castilla, chinche de Castilla, gallo de la tierra, paloma de Castilla, gallina de Castilla, gallina de la tierra, cáñamo de la tierra...

2. Introducción de un americanismo para designar al nuevo referente, y que, como señala Frago (1992), "es un claro exponente de la adaptación del español al medio indiano y, por consiguiente, constituye un fiel reflejo de la tendencia criollizadora de la lengua, en el sentido más ampliamente cultural del término". El Compendio de Pantaleón de Guzmán incluye americanismos que a comienzos del siglo XVIII debían estar incorporados a la lengua española (cacao, yuca, chile, magüey, tabaco, guayacán, guayaba...), americanismos que tienen en el Compendio su primera documentación lexicográfica ${ }^{15}$ (cfr. RAE 2000 y Nieto Jiménez y Alvar Ezquerra 2007) y americanismos no documentados en otras obras (quilete, catarnica, cesonte/ cezontle, curruchiche, chinchitor, tepenchile...) y que, probablemente, no serían generales:

atepocate $\rightarrow$ primera documentación: DRAE, 1884, "renacuajo" bagre $\rightarrow$ primera documentación: Terreros, 1787, "especie de pescado, que se halla en los mares de Guayaquil"

chamborote $\rightarrow$ primera documentación: Alemany y Bolufer, 1917, "en Guatemala dícese de un pimiento blanco" chayote $\rightarrow$ primera documentación: Terreros, 1787, "fruta de Méjico, a modo de melón: la cáscara es verde y llena de espinas, tiene solo una pepita que se da a los atabardillados, como también la fruta, que solo se come cocida"

chichicaste $\rightarrow$ primera documentación: Alemany y Bolufer, 1917, "en Méjico y Guatemala ortiga"

\footnotetext{
14 Algunas de estas voces ( piñuela, aguacatillo, piojillo, tortuguilla ...) han entrado en el DRAE como denominaciones de plantas o animales propios de América.

15 Algunas de estas voces (ahiote, amate, chacha, chía/chían, coyote, pacaya, pitajaya, quetzal, tecolote, ule) sí están documentadas en cronistas de Indias y recogidas en el Vocabulario de indigenismos en las crónicas de Indias de Alvar Ezquerra (1997).
} 
chilacayote $\rightarrow$ primera documentación: Autoridades, 1726, “especie de calabaza sumamente grande, y de mui poco peso, de la qual se hace un dulce mui agradable refrigerante y sabroso. Es planta que vino de Indias, y con ella el nombre, y que ha producido abundantíssimamente en Andalucía, pues como de antes usaban de las parras en los patios, ahora usan emparrados de los chilacayotes"

chiltote $\rightarrow$ primera documentación: Alemany y Bolufer, 1917, “en Méjico, bebida que se hace con pulque y chile"

chipilín $\rightarrow$ primera documentación: Alemany y Bolufer, 1917, “en Guatemala chipile [nombre que dan en Méjico a un género de plantas leguminosas]"

cotuza/cotusa $\rightarrow$ primera documentación: Alemany y Bolufer, 1917, “en Guatemala y Salvador, agutí [mamífero subungulado roedor, cuya piel se utiliza para vestidos. Es muy parecido a la cabra enana de almizcle y vive en la Guayana, Brasil y Perú]"

guaruma/guarumo $\rightarrow$ primera documentación: Alemany y Bolufer, 1917, "nombre vulgar americano de un árbol artocárpeo"

ichintal $\rightarrow$ primera documentación: Alemany y Bolufer, 1917, “en Guatemala, raíz de la chayotera"

iguana $\rightarrow$ primera documentación: Stevens, 1706, "so they call the alligators in some parts of the West Indies"

jocote $\rightarrow$ primera documentación: Alemany y Bolufer, 1917, “en América Central, especie de jobo o ciruelo"

juilín $\rightarrow$ primera documentación: Alemany y Bolufer, 1917, “en Guatemala, pececillo de río"

milpa $\rightarrow$ primera documentación: Terreros, 1787, "llaman en México al maizal o campo de maíz"

olote $\rightarrow$ primera documentación: Alemany y Bolufer, 1917, “en Méjico, raspa de las panojas de maíz"

panjil $\rightarrow$ primera documentación: DRAE, 1884, "árbol del Paraíso"

pijije $\rightarrow$ primera documentación: Alemany y Bolufer, 1917, "nombre que dan en Guatemala y el Salvador a un género de aves acuáticas"

pizote $\rightarrow$ primera documentación: Alemany y Bolufer, 1917, “en Guatemala y Salvador uno de los nombres del coatí"

quagilote/cuajilote $\rightarrow$ primera documentación: Terreros, 1787, "fruta de Méjico, parecida al plátano; al comerla se hace como un estropajo en la boca"

sompopo $\rightarrow$ primera documentación: Alemany y Bolufer, 1917, "nombre que dan en Honduras a cierta especie de hormiga"

sopilote $\rightarrow$ primera documentación: Terreros, 1787, "llaman en Nueva España a una ave de la magnitud de un pavo, todo negro, que se alimenta de las carnes muertas. En Caracas le llaman zamuro, y en el nuevo Reyno 
de Granada gallinazo. Sirven de limpiar el terreno de putrefacciones, y no quieren parar en la Isla de Santo Domingo, si los llevan a ella" taltusa $\rightarrow$ primera documentación: Alemany y Bolufer, 1917, "tuza [Amér. Centr. nombre vulgar de un pequeño mamífero roedor]" taquazín/tacuacín $\rightarrow$ primera documentación: DRAE, 1925, “Amér. Centr. y Méj. Zarigüeya"

tepemechín $\rightarrow$ primera documentación: Alemany y Bolufer, 1917, "hermoso pez de Guatemala"

tepezcuinte/tepezcuintle $\rightarrow$ primera documentación: DRAE, 1984, "Guat. Tepeizcuinte [paca, animal]"

3. En otras ocasiones, la voz americana va acompañada de la voz utilizada en España: pulga o nigua, búho o tecolote, llaga acançerada o ychan çicat, cáñamo o pita, caña o elote, bragas o mastate, chichicaste o ortiga, maizal $o$ troje... pues es frecuente, sobre todo en los primeros textos, el uso de sinónimos o equivalentes entre ambas lenguas, debido a que el "escritor aun no se siente familiarizado con el exótico vocabulario, quizá tampoco con la realidad objeto de su designación, y [...] asimismo tal vez teme que esas extrañas palabras no serán comprendidas por sus lectores" (Frago Gracia 1992).

4. Finalmente, Pantaleón de Guzmán incluye en el Compendio voces hispanas cakchiquelizadas, fruto del paso a Indias de animales y plantas de origen europeo; así ocurre, por ejemplo, con nauox, los nabos; lechugax, las lechugas; rábanox, los rábanos; sanajorio, las zanahorias; culix, las coles; perexil, el perejil; avax, las habas; arvexax, las alberjas; carbanxox, los garbanzos; cranata, las granadas; berenxena, las berenjenas; calabaxa, las calabazas; pipin, los pepinos.

\section{EL COMPENDIO DE PANTALEÓN DE GUZMÁN Y LAS NOMENCLATURAS DEL ESPAÑOL: LAS FUENTES}

Pese a desconocer los antecedentes directos que sirvieron a Pantaleón de Guzmán para la redacción de su obra, el Compendio no es una obra original en la historia de la lexicografía del español; desde finales del siglo XV y a lo largo de cinco siglos se compusieron numerosas nomenclaturas que, como señala Manuel Alvar Ezquerra (2013: 19-20), se desarrollaron "con una finalidad práctica inmediata, y de eminente carácter didáctico, en las 
que se hace una clasificación de la realidad extralingüística, esto es, de las ideas que tenemos de las cosas, de manera que el mundo queda parcelado, repartiéndose el vocabulario a lo largo de esas divisiones".

El Compendio de Guzmán es un buen ejemplo de la escasa lexicografía amerindia temática. No cabe duda de que nuestro franciscano, así como el resto de misioneros ${ }^{16}$, conocía la obra de Antonio de Nebrija ${ }^{17}$-tras cuyas Introductiones latinae (a partir de la edición 1493) se encuentra una nomenclatura titulada "Lexicon seu parvum vocabularium"-y seguramente la de otros muchos lexicógrafos que incorporaron repertorios similares tras sus gramáticas, artes y vocabularios. El éxito que alcanzaron las nomenclaturas en la enseñanza de segundas lenguas explicaría su traslado a América y su adaptación para el aprendizaje de lenguas indígenas.

Pantaleón de Guzmán debió, entonces, adaptar algún repertorio temático bilingüe anterior (probablemente sustituyó la lengua extranjera que apareciera por el cakchiquel) y elaborar uno nuevo con el léxico que le pareció más necesario y útil para su labor evangelizadora: el perteneciente a la realidad inmediata y el relativo a la religión católica. Así nació el Libro yntitulado Compendio de nombres en lengua cakchiquel.

\section{CONCLUSIONES}

El Compendio de nombres en lengua cakchiquel de Pantaleón de Guzmán es una buena muestra de la labor lingüística realizada por los misioneros en tierras americanas.

El proceso de evangelización obligó a nuestros religiosos a aprender lenguas indígenas para comunicarse con los indios, y de esa relación surgieron numerosos diccionarios y gramáticas que se componían para uso

16 Un léxico ordenado en varias materias está presente, desde el Arte de la lengua mexicana de Andrés de Olmos (1547), en la mayoría de las gramáticas o artes de lenguas amerindias.

17 Las Introductiones latinae de Nebrija fueron, sin duda alguna, el manual más utilizado para el aprendizaje de la lengua latina en estos siglos; por ello, se convirtieron, por real decreto, en el único texto oficial en 1598. En América también fueron muy conocidas: en la casi totalidad de libros de embarque, registro de aduanas y libros de transacciones se mencionan ejemplares de las Introducciones, de manera que "podría decirse que en casi todas las partidas de libros figuran sus obras [las de Antonio de Nebrija], destacándose de esta manera como el autor español más difundido en la Colonia” (Torre Revello 1991: 207). 
de la comunidad con el fin de disponer de herramientas útiles y válidas que ayudaran a la conversión de los indios. Ello explicaría que muchos de estos manuales solo fueran utilizados en el seno de uno o varios conventos y que nunca llegaran a la imprenta.

El Compendio abandona la ordenación alfabética, habitual en la mayoría de repertorios, y se decanta por distribuir sus materiales a partir de una serie de ámbitos designativos, disposición que facilitaría el aprendizaje del cakchiquel y, por tanto, una comunicación más rápida y efectiva con los indios. Pese a que metodológicamente es una obra poco sistemática, resuelve con cierto éxito los problemas que le causan las diferencias entre ambas lenguas y las dificultades que entraña el acercamiento a realidades absolutamente desconocidas, y muestra el considerable caudal léxico, en forma de americanismos, neologismos e hispanismos, que manejaba Pantaleón de Guzmán.

El análisis del Compendio es, en definitiva, una aportación a la historia de la lingüística misionera, a los estudios de lenguas en contacto, a la historia de la lexicografía del español, que muestra el valor y la riqueza de unos materiales que se enmarcan

en una tradición de estudios de las lenguas vernáculas de América, que tuvo sus orígenes a mediados del siglo xvI, cuando un grupo de franciscanos logró codificar la lengua náhuatl o mexicana y la tarasca o purépecha en gramáticas y vocabularios. Y cabe advertir que, en un momento en el que el Renacimiento hacía suyas y ponía en molde latino las tradiciones hebrea y árabe, en el Nuevo Orbe emergía una nueva tradición gramatical que enriquecía el saber lingüístico con estructuras nunca antes conocidas (Hernández de León-Portilla 2012: 102).

\section{REFERENCIAS BIBLIOGRÁFICAS}

AcostA, José DE. 1590 [1987]. Historia natural y moral de las Indias, edición de José Alcina Franch. Madrid: Historia 16.

Aleza Izquierdo, Milagros - Enguita Utrilla, José Ma (2002): El español de América: aproximación sincrónica. Valencia: Tirant Lo Blanch.

Alvar, Manuel (coord.). 1997. Manual de dialectología hispánica. El español de América. Barcelona: Ariel.

Alvar Ezquerra, Manuel. 1987. Apuntes para la historia de las nomenclaturas en español. En Actas del VII Congreso Internacional de Lingüistica y Filología de América Latina (ALFAL). Homenaje a Pedro Henríquez Ureña. Santo Domingo, República Dominicana, 1984, vol. I, pp. 457-470. Santo Domingo: Universidad Nacional Pedro Henríquez Ureña. 1997. Vocabulario de indigenismos en las Crónicas de Indias. Madrid: CSIC. 
2013. Las nomenclaturas del español. Siglos XV-XIX. Madrid: Liceus.

Ayala CAstro, M. Concepción. 1992a. El concepto de nomenclatura. En M. Alvar Ezquerra (ed.). Actas del IV Congreso Internacional Euralex'90, pp. 437-444. Barcelona: Biblograf.

1992b. Nomenclatures de l'espagnol (1526-1800). Considérations générales sur la nature et la fonction des nomenclatures. Cahiers de lexicologie LXI: 127-160.

Сото, Тнома́s DE. 1656 [1983]. [Thesavrvs Verborum] Vocabvlario de la lengua Cakchiquel v[el] Guatmalteca, nueuamente hecho y recopilado con summo estudio, trauajo y erudición. Edición de René Acuña. México: Instituto de Investigaciones Filológicas, Universidad Nacional Autónoma de México.

Enguita Utrilla, José María. 2004. Para la historia de los americanismos léxicos. Fráncfort/ Berlín/Berna/Bruselas/Nueva York/Oxford/Viena: Peter Lang.

Flores, Ildefonso José. 1753. Arte de la lengva metropolitana del reyno cakchiquel o gvatemalico. Guatemala: Sebastián Arévalo.

Fontanella de Weinberg, M. Beatriz. 1992. El español de América. Madrid: MAPFRE.

Frago Gracia, JuAN ANTONIO. 1992. Estrategias para la investigación en el español americano hasta 1656. En Actas del Congreso de la Lengua española. La lengua española: unidad $y$ diversidad. Sevilla: Centro Virtual Cervantes [http://cvc.cervantes.es/obref/congresos/ sevilla/unidad/ponenc_gracia.htm]

1999. Historia del español de América: textos y contextos. Madrid: Gredos.

García Aranda, M. ángeles. 2013. Las gramáticas y los vocabularios de las lenguas indigenas: el cakchiquel. Lugo: Axac.

García Ruiz, Jesús. 1992. El misionero, las lenguas mayas y la traducción. Nominalismo, Tomismo y Etnolingüismo en Guatemala. Archives de Sciences Sociales des Religions 77: 83-110.

GRANDA, GERMÁN DE. 1994. Español de América, español de África y hablas criollas hispánicas. Madrid: Gredos.

GuZMÁn, Pantaleón DE. 1704 [1984]. Compendio de nombres en lengua caqchiquel. Edición de René Acuña. México: Instituto de Investigaciones Filológicas, Universidad Nacional Autónoma de México.

Herbruger, Alfredo y Eduardo Díaz Barrios. 1956. Método para aprender a hablar, leer y escribir la lengua cakchiquel. Guatemala: Tip. Nacional.

Hernández de León-Portilla, Ascensión. 1993. Nebrija y el inicio de la lingüística mesoamericana. Anuario de Letras 31: 205-223.

2009. El Arte de la lengua mexicana y castellana de fray Alonso de Molina: morfología y composición. Estudios de Historia novohispana 39: 167-206.

2012. La tradición gramatical mesoamericana. Sus orígenes y formas de expresión. En E. Battaner, V. Calvo y P. Peña (eds.). Historiografía lingüística: líneas actuales de investigación, pp. 101-115. Münster: Nodus Publikationen.

Hernández Hernández, Esther. 2008a. Indigenismos en el Vocabulario de la Lengua Cakchiquel atribuido a fray Domingo de Vico, Ms. BNF R. 7507. Revista de Filología Española 88/1: 67-88. 22: 189-211.

InSTITUTO INDIGENISTA NACIONAL. 1950. Alfabeto para los cuatro idiomas indigenas mayoritarios de Guatemala: quiché, cakchiquel, mam y kekchí. Guatemala: Ministerio de Educación Pública.

Kaufman, Terence. 1974. Idiomas de Mesoamérica. Guatemala: Ministerio de Educación / Editorial José Pineda Ibarra. 
KoERnER, KonRAD. 2006. Gramática de las lenguas castellana de Antonio de Nebrija y el estudio de las lenguas indígenas americanas: o hacia una historia de la lingüística amerindia. En R. Escavy et al. (eds.). Caminos actuales de la Historiografía Lingüística. Actas del V Congreso Internacional de la SEHL, vol. II, pp. 17-36. Murcia: Servicio de Publicaciones.

Lipski, John. 1996. El español de América. Madrid: Cátedra, $2^{\mathrm{a}}$ ed.

López Morales, Humberto. 1998. La aventura del español en América. Madrid: Espasa.

Lucena Salmoral, Manuel. 1982. Historia general de España y América: hasta fines del siglo XVI. El descubrimiento y la fundación de los reinos ultramarinos. Madrid: Ediciones Rialp.

Medina Escudero, Miguel Ángel. 1988. Métodos y medios de evangelización de los dominicos en América. En Actas del I Congreso internacional sobre los dominicos y el Nuevo Mundo. Sevilla: 21-25 de abril de 1987, pp. 157-207. Madrid: Deimos.

Molina, Alonso de. 1571. Arte de la lengua mexicana y castellana. México: Pedro Ocharte.

Nieto Jiménez, Lidio y Alvar Ezquerra, Manuel. 2007. Nuevo Tesoro Lexicográfico del español. S. XIV-1726. Madrid: Arco/Libros, 11 vols.

Olmos, ANDRÉs DE. 1547[2002]. Arte de la lengua mexicana. Edición facsimilar y estudio introductorio de Ascensión Hernández y Miguel León-Portilla. México: UNAM.

Oxlajuuj Kees Maya’ Aut'ib. 1993. Los idiomas mayas de Guatemala. Guatemala: Centro Educativo y Cultural maya.

Ramírez Luengo, José Luis. 2007. Breve historia del español de América. Madrid: Arco/Libros.

Real Academia Española. 2000. Nuevo Tesoro Lexicográfico de la Lengua Española. Madrid: Espasa Calpe, DVD-ROM.

RidRuejo, EmiLIo. 2007. Lingüística misionera. En Josefa Dorta, Cristóbal Corrales y Dolores Corbella (eds.). Historiografia de la lingüistica en el ámbito hispánico. Fundamentos epistemológicos y metodológicos, pp. 435-477. Madrid: Arco/Libros.

Rivarola, José Luis. 2000. El español de América en su historia. Valladolid: Universidad de Valladolid.

Rosales, Carlos Joseph. 1748 [1920]. Gramática del idioma cakchiquel. Edición de Daniel Sánchez García. Guatemala: Tipografía San Antonio.

SÁnchez Méndez, Junn. 2003. Historia de la lengua española en América. Valencia: Tirant lo Blanch.

Smailus, Ortwin. 1989. Vocabulario en lengua castellana y guatemalteca que se llama Cakchiquel Chi. Análisis gramatical y lexicológico del Cakchiquel Colonial según un antiguo diccionario anónimo. Hamburg: Wayasbah Publication. 3 vols.

Smith Stark, Thomas C. 2010. La trilogía catequística: artes, vocabularios y doctrinas en la Nueva España como instrumento de una política lingüística de normalización. En R. Barriga y P. Martín Butragueño (dirs.). Historia sociolingüística de México, pp. 451-482. México: El Colegio de México.

Suárez Roca, José Luis. 1991. Lenguas indígenas del Nuevo Mundo. Gramáticas y vocabularios de la lengua mexicana (s. xvi-xviii). Oviedo: Universidad de Oviedo.

1992. Lingüistica misionera española. Oviedo: Pentalfa.

Sueiro Justel, Joaquín. 2002. La política lingüistica española en América y Filipinas (siglos xvi-xix). Lugo: TrisTram.

Torres Torres, Antonio. 1998. José de Acosta y los americanismos léxicos de base hispánica. Interlingüistica 9: 327-330.

Torre Revello, José. 1991. El libro, la imprenta y el periodismo en América durante la dominación española. México: UNAM.

Vaquero de Ramírez, María. 1996. El español de América II. Morfosintaxis y léxico. Madrid: Arco/Libros. 
Varea, Francisco De. 1699[1997]. Calepino en lengua cakchiquel. Edición de Judy Garland Butler. Guatemala: Universidad Mariano Gálvez.

VÁzquez, Francisco. 1714[1937-1944]). Crónica de la Provincia del SS. Nombre de Jesús de Guatemala. Prólogo, notas e índices de L. Lamadrid. Guatemala: Sociedad de Geografía e Historia.

Villacañas, Benito De. 2011. El Arte y el Vocabulario de la lengua cakchiquel. Estudio y edición facsimilar de M. a Ángeles García Aranda. Toledo: Diputación Provincial de Toledo.

Ximénez, fray Francisco. 1722 [1930]. Historia de la Provincia de San Vicente de Chiapa y Guatemala de la Orden de los Predicadores. Guatemala: Sociedad de Geografía e Historia de Guatemala. 3 vols.

1985. Primera parte del Tesoro de las Lenguas cackchiquel, quiché y tzutuhil, en que las dichas lenguas se traducen a la nuestra, española, de acuerdo con los manuscritos redactados en la Antigua Guatemala a principios del siglo xviii y conservados en Córdoba (España) y Berkeley (California). Edición crítica por Carmelo Sáenz de Santa María. Guatemala: Academia de Geografía e Historia de Guatemala.

1993. Arte de las tres lenguas kaqchikel, fiché y tzutuhil (ms. en la Biblioteca Newberry, Chicago, Illinois). Transcripción, notas y prólogo por Rosa Helena Chinchilla. Guatemala: Academia de Geografía e Historia de Guatemala.

Zimmermann, Klaus (ed.). 1997. La descripción de las lenguas amerindias en la época colonial. Frankfurt am Main / Madrid: Vervuert / Iberoamericana.

Zwartues, ОTto (ed.). 2000. Las gramáticas misioneras de tradición hispánica (siglos xvixvii). Ámsterdam: Rodopi B.V. 